\title{
ROLE OF COMMUNITY PHARMACIST AND NUTRITIONISTS IN OBESITY MANAGEMENT: A LITERATURE REVIEW
}

\author{
MADEEHA MALIK*, NATASHA KANWAL, AZHAR HUSSAIN \\ Department of Pharmacy, Hamdard Institute of Pharmaceutical Sciences, Hamdard University, Islamabad Pakistan. \\ Email: madeehamalik15@gmail.com
}

Received: 09 October 2016, Revised and Accepted: 01 November 2016

\section{ABSTRACT}

The idea of engaging community pharmacists and nutritionists in weight management services has been well accepted by the community, as both can help to improve behavior and knowledge regarding obesity among obese patients. The aim of this study is to summarize research findings from developed and developing countries as well as from Pakistan regarding role of community pharmacists and nutritionists in obesity management. A total of 38 studies were reviewed regarding trends in obesity management. The review concluded that the role of community pharmacists and nutritionists in obesity management is not well acknowledged in most of the developing countries including Pakistan. Limited data are available on a number of nutritionists and type of services provided by them for weight management in these countries. There is urgent need to identify the barriers and gaps to further enhance the effectiveness of obesity management. Beside this intervention studies involving multi-disciplinary healthcare professionals must be designed to control current obesity crisis worldwide.

Keywords: Community pharmacists, Counseling, Nutritionists, Obesity, Weight management program.

(C) 2017 The Authors. Published by Innovare Academic Sciences Pvt Ltd. This is an open access article under the CC BY license (http://creativecommons. org/licenses/by/4. 0/) DOI: http://dx.doi.org/10.22159/ajpcr.2017.v10i2.15604

\section{INTRODUCTION}

Obesity is a major health problem which requires effective interventions for its prevention and treatment. Evidence supports that physical activity, when combined with modifications to energy consumption, is the most important behavioral approach for preventing obesity [1,2]. Barriers in the management of obesity include lack of knowledge regarding obesity as a chronic disease, low socioeconomic status, time limitations, and a number of comorbidities including sleep, mental health, chronic pain, cardiovascular, musculoskeletal, respiratory, endocrine, and digestive disorders. A few medications used as treatment of some of these diseases may also slow down weight-loss process. Besides this lack of training of health-care professionals for obesity management in relation to standard treatment guidelines, attitudes, and their beliefs regarding available anti-obesity treatment are important factors which need to be addressed [3].

Health professionals need to identify, acknowledge and address these potential barriers to increase patient weight loss and compliance with available treatments [4,5]. Supportive environment and societies are important in determining people's choices for healthy nutrition and regular exercise as the most convenient, accessible, available, and affordable choices for preventing obesity [6]. Health-care professionals need to be adequately trained to manage obesity including assessment of patient approaches regarding lifestyle modifications and using dietitian and other recommendations for weight loss counseling $[7,8]$. Pharmacists are well acknowledged as appropriate personal to help people in managing their weight and promoting healthy lifestyle in the developed countries $[9,10]$. The idea of engaging community pharmacists and nutritionists in weight management services has been well-accepted by the community, as both can help to improve behavior and knowledge regarding obesity among obese patients [11-13]. Although community pharmacy weight management programs have been reported successful in weight management in many developed countries, still need for additional training and educational resources for pharmacy staff has been emphasized for effective pharmacy weight management services $[14,15]$. The aim of this paper is to highlight the issues faced by health-care professionals in obesity management worldwide by reviewing the past and present literature. The main objective is to systematically identify and review the role of community pharmacists and nutritionists in obesity management worldwide.

\section{METHODS}

The electronic databases PubMed, Google Scholar, and Science Direct, were searched for articles published from 1990 to 2015. The search terms used with each database were obesity, weight management, pharmacists, nutritionists, and dieticians. Full-text papers, as well as abstracts, were retrieved and included in review. A total of 38 studies were retrieved from databases related to role of health-care professionals in obesity management. The studies were categorized on the basis of their country of publishing into developed countries, developing countries, and Pakistan. 26 studies from developed countries, 10 from developing countries, and 2 studies from Pakistan were included in this review (Table 1). Quantitative cross-sectional surveys, as well as qualitative studies, were also included in this study.

\section{RESULTS AND DISCUSSION}

Patient counseling regarding lifestyle modifications including lowcalorie diet increased physical activity, and behavioral approach is required for the appropriate management of obesity [16]. Pharmacist is an important and easily accessible member of health-care team and must be well equipped with disease-specific knowledge, attitudes, and skills to support his/her roles [14]. Studies conducted in developing countries have identified that pharmacists are occasionally involved in counseling of obese patients and adequate training of health professionals for appropriate obesity management has been underlined $[17,18]$.

Overview of obesity management in developed and developing countries

Over eating of unhealthy foods, dieting, personal factors, and physical inactivity have been reported as important risk factors for obesity. Although in many cases, patients were reported conscious regarding 
Table 1: Details of country and number of included papers

\begin{tabular}{lll}
\hline Regions & Number of studies & Countries \\
\hline Developed countries & 26 & $\begin{array}{l}\text { USA, Australia, UK, Japan, Germany, Belgium, Switzerland, Sweden, Canada, Denmark, Greece, } \\
\text { Spain, Italy, Finland, Ireland, Netherlands }\end{array}$ \\
$\begin{array}{ll}\text { Developing countries } \\
\text { Pakistan }\end{array}$ & 10 & \\
Total & 2 & \\
\hline
\end{tabular}

obesity-associated health risks and agreed that maintaining ideal body weight is healthier most of them do not maintain it [15]. Evidence shows 90 minutes of physician-delivered weight management instruction over 6 months achieved greater weight loss than the standard medical care $[19,20]$.

The majority of the obstetrician gynecologist's most in developed as well as developing countries most likely use body mass index for obesity screening and to counsel their patients about weight control, balanced diet, and physical activity. Many of them, however, do not prescribe weight loss medications or refer their obese patients to behavioral weight loss treatment $[21,22]$.

Effective approaches for weight loss involve dietary therapy, physical activities along with behavioral interventions [16]. Weight loss can be accomplished through a decrease in the calories intake and increased exercise. Weight maintenance requires long-term behavioral change combined with regular moderate exercise, less fat intake, increased intake of fruits and vegetable as well as social support. Crash diets and medications are not the real answer to long-term weight management $[19,23]$. Along with patients, physicians should also be educated regarding the benefits of moderate and effective weight loss approaches [24,25]. Different interventions, including communitybased strategies, are required to address this complex health problem in developed as well as developing world [26]. Treatment involving multidisciplinary team including general practitioners, pediatricians, specialized dieticians, nutritionists, and community pharmacists seems to be the way to combat the obesity epidemic in the developing countries [27].

Overview of role of nutritionists/dieticians and community pharmacists in obesity management in developed and developing countries

Physicians need to be trained to manage obesity including assessing patient attitudes about making lifestyle modifications and using dietitian and other referrals for weight loss counseling [7,28]. Pharmacists are considered the most appropriate personal to promote weight management after adequate training [29]. The community pharmacy weight management program can contribute in reduction of weight and waist circumference in patients. Successful weight management has been reported by both meal replacement program and a conventional reduced-calorie diet at community pharmacies [14]. Several studies reported that respondents appreciated the idea of receiving weight management services by pharmacists at community pharmacies [12-14,30]. Women pharmacy customers had positive views and attitude regarding the participation of pharmacists in their desired weight management program [12]. Pharmacy based program have been reported more effective than GPs, with a considerably greater retention rate of participants and weight maintenance after weight loss. However, lack of time, patient demand, and incentives are few of the identified barriers towards regular counseling by the pharmacists [31]. Although pharmacists and pharmacy assistants have been involved in providing weight management services to patients in developed world, their advice is not much evidence based which highlight need for their training for the provision of effective pharmacy weight management services [32].

On the other hand, community pharmacists in developing countries, counseled obese patients occasionally, although they were comfortable with counseling about obesity management. Female pharmacists were reported better in knowledge of weight management than male pharmacists [33]. The barriers identified to obesity counseling by pharmacists were lack of patient's awareness regarding pharmacists' expertise in counseling and perceptions of pharmacist that obese patients lack determination, will power to lose weight and were nonadherent to weight reduction interventions [17]. A successful obesity management can be achieved by a multidisciplinary team, including a physician, dietitian, behavioral therapist, exercise expert, nurses, and pharmacist [34]. Dietitians follow a lifestyle modification approach for weight management in Canada. Nutritionists have been reported most suitable to provide weight management counseling to obese patients [11]. The need for educational intervention in dietetics and nutritionists training with emphasis on increasing awareness of weight bias in existing curriculum was recommended [35]. Online courses for nutritionist professionals and other health-care professionals are effective for increasing the knowledge, skills, and self-efficacy of the professionals in using an ecological approach to prevent and manage obesity [36]. Although strategies have been implemented to supplement effective nutrition management, still little research has been conducted on the effectiveness and cost implications of these interventions, especially in developing countries. The approaches toward assessment and behavioral management strategies in the management of obesity should be homogenized. Besides this, the counseling skills of nutritionists and other allied health professionals specializing in obesity management must be emphasized [37].

\section{Overview of obesity management in Pakistan}

According to the World Health Organization, $25.5 \%$ of the women and $18.8 \%$ of the men are overweight while $1 \%$ of the men and $3.6 \%$ of the women are obese in Pakistan. The prevalence of obesity is generally reported higher in women as compared to men and relatively more in urban population [6]. The population aged between 45 and 64 years are at 2 times increased risk of being overweight as compared to 18 to $<35$ years of age in Pakistan [38]. The physicians recognize obesity as a rising problem in Pakistan, but they do not possess knowledge regarding its complexities neither are significantly trained to treat it successfully. They are hardly trained on acquiring counseling skills related to diet, nutrition, and healthy lifestyles [39]. Similarly, the role of nutritionists and community pharmacist in obesity management is not well perceived by the community as well as by different stakeholders. They are hardly involved in obesity management in Pakistan. Despite the importance of nutrition, it has seldom considered an integral component of medical education. Medical educators have recognized the need for including nutrition education in the medical curriculum. Low knowledge of doctors and medical students regarding nutrition and weight management has been reported in Pakistan [40]. The standard of nutrition education in the medical curriculum need to be improved by significantly increasing the nutrition component of the pediatric curriculum and incorporating the planning of diets for childhood, pregnancy, and lactation as well as for different diseases into the community medicine and pharmacy curriculum.

\section{CONCLUSION}

The review concluded that rapid urbanization, lifestyle modification, high energy dense diets, and minimal physical activity are identified factors continuously contributing toward obesity crisis globally. Screening and treatment for diseases get delayed as overweight 
individuals are mostly reluctant to seek medical care for their obesity, as they are certain of their humiliation. Physical exercise and dietary measures to control body weight are lacking in spite of the community desire to have appropriate body weight. This is due to lack of awareness among community regarding healthy lifestyle and role of health-care professionals in weight management. Patient education programs to control obesity have been ignored. The role of community pharmacists and nutritionists in obesity management is not well-acknowledged in most of the developing countries including Pakistan. Limited data are available on number of nutritionists and type of services provided by them for weight management in these countries. There is urgent need to identify the barriers and gaps to further enhance the effectiveness of obesity management. Besides this intervention studies involving multidisciplinary health-care professionals must be designed to control current obesity crisis worldwide.

\section{REFERENCES}

1. Jakicic JM, Otto AD. Physical activity considerations for the treatment and prevention of obesity. Am J Clin Nutr 2005;82 1 Suppl:226S-9.

2. Warburton DE, Nicol CW, Bredin SS. Health benefits of physical activity: The evidence. CMAJ 2006;174(6):801-9.

3. Harvey EL, Summerbell CD, Kirk SF, Hill AJ. Dietitians' views of overweight and obese people and reported management practices. J Hum Nutr Diet 2002;15(5):331-47.

4. Mauro M, Taylor V, Wharton S, Sharma AM. Barriers to obesity treatment. Eur J Intern Med 2008;19(3):173-80.

5. Moore H, Summerbell CD, Greenwood DC, Tovey P, Griffiths J, Henderson $\mathrm{M}$, et al. Improving management of obesity in primary care: Cluster randomised trial. BMJ 2003;327(7423):1085.

6. WHO. Obesity and Overweight Fact Sheet N311. 2015. 4/9/2015. Available from: http://www.who.int/mediacentre/factsheets/fs311/en/.

7. Davis NJ, Emerenini A, Wylie-Rosett J. Obesity management: Physician practice patterns and patient preference. Diabetes Educ 2006;32(4):557-61.

8. Huda AH, Yousif AR, Israa MM. Knowledge, attitude and practice regarding obesity management among family and non family physicians working in primary health care centers in Baghdad. Iraqi Postgrad Med J 2012;10(1):6-12.

9. Fox NJ, Ward KJ, O'Rourke AJ. The 'expert patient': Empowerment or medical dominance? The case of weight loss, pharmaceutical drugs and the Internet. Soc Sci Med 2005;60(6):1299-309.

10. Boardman HF, Avery A. Effectiveness of a community pharmacy weight management programme. Int J Clin Pharm 2014;36(4):800-6.

11. Bleich SN, Bandara S, Bennett W, Cooper LA, Gudzune KA. Enhancing the role of nutrition professionals in weight management: A cross-sectional survey. Obesity (Silver Spring) 2015;23(2):454-60.

12. Fakih S, Hussainy S, Marriott J. Women pharmacy consumers' experiences with weight loss treatment across Victoria, Australia. Int J Clin Pharm 2013;35(6):1120-9.

13. Weidmann AE, Cunningham S, Gray G, Hansford D, Bermano G, Stewart D. Views of the Scottish general public on community pharmacy weight management services: International implications. Int $\mathrm{J}$ Clin Pharm 2012;34(2):389-97.

14. Ahrens R, Hower M, Best A. Effects of weight reduction interventions by community pharmacists. J Am Pharm Assoc 2003;43(5):583-9.

15. O’Neal KS, Crosby KM. Patients' perceptions of a pharmacist-managed weight management clinic in a community setting. Res Social Adm Pharm 2013;9(1):129-36.

16. Lang A, Froelicher E. Management of overweight and obesity in adults: Behavioral intervention for long-term weight loss and maintenance. Eur J Cardiovasc Nurs 2006;5(2):102-14

17. Awad A, Waheedi M. Community pharmacists role in obesity treatment in Kuwait: A cross-sectional study. BMC Public Health 2012;12:863.

18. Barratt J. Diet-related knowledge, beliefs and actions of health professionals compared with the general population: An investigation in a community Trust. J Hum Nutr Dietet 2001;14(1):25-32.

19. Davis Martin P, Rhode PC, Dutton GR, Redmann SM, Ryan DH, Brantley PJ. A primary care weight management intervention for low-income African-American women. Obesity (Silver Spring) 2006;14(8):1412-20.

20. Puhl R, Wharton C, Heuer C. Weight bias among dietetics students: Implications for treatment practices. J Am Dietetic Assoc 2009;109(3):438-44.

21. Weiss JL, Malone FD, Emig D, Ball RH, Nyberg DA, Comstock CH, et al. Obesity, obstetric complications and cesarean delivery rate--A population-based screening study. Am J Obst Gynecol 2004;190(4):1091-7.

22. Robert IB, Wadden TA, Tershakovec AM, Cronquist JL. Behavior therapy and sibutramine for the treatment of adolescent obesity a randomized controlled trial. J Am Med Assoc 2003;289(14):1805-12.

23. Basu S, Vellakkal S, Agrawal S, Stuckler D, Popkin B, Ebrahim S. Averting obesity and type 2 diabetes in India through sugar-sweetened beverage taxation: An economic-epidemiologic modeling study. PLoS Med 2014;11(1):e1001582.

24. Phelan S, Nallari M, Darroch FE, Wing RR. What do physicians recommend to their overweight and obese patients? J Am Board Fam Med 2009;22(2):115-22.

25. Um IS, Armour C, Krass I, Gill T, Chaar BB. Weight management in community pharmacy: What do the experts think? Int J Clin Pharm 2013;35(3):447-54.

26. Lloyd KB, Thrower MR, Walters NB, Krueger KP, Stamm PL, Evans RL. Implementation of a weight management pharmaceutical care service. Ann Pharmacother 2007;41(2):185-92.

27. van Gerwen M, Franc C, Rosman S, Le Vaillant M, Pelletier-Fleury N. Primary care physicians' knowledge, attitudes, beliefs and practices regarding childhood obesity: A systematic review. Obes Rev 2009; 10(2):227-36

28. Low S, Chin MC, Ma S, Heng D, Deurenberg-Yap M. Rationale for redefining obesity in Asians. Ann Acad Med Singapore 2009;38(1):66-9.

29. Dressler H, Smith C. Food choice, eating behavior, and food liking differs between lean/normal and overweight/obese, low-income women. Appetite 2013;65:145-52.

30. Veronica GP, Coles C, Logan BN, Davis L. The LIFE project: A community-based weight loss intervention program for rural African American women. Fam Community Health 2010;33(2):133-43.

31. Mills S. Evaluation of an adult weight management service delivered by pharmacies and GP practices. University of Chester; 2011.

32. Krska G, Lovelady C, Connolly D, Parmar S, Davies MJ. Community pharmacy contribution to weight management: Identifying opportunities. Int J Pharm Pract 2010;18(1):7-12.

33. Jaworowska A, Bazylak G. An outbreak of body weight dissatisfaction associated with self-perceived BMI and dieting among female pharmacy students. Biomed Pharmacother 2009;63(9):679-92.

34. Nowicka P. Dietitians and exercise professionals in a childhood obesity treatment team. Acta Paediatr Suppl 2005;94(448):23-9.

35. Rebecca P, Kelly DB. Bias, discrimination, and obesity. Obes Res J 2012;9(12):788-805.

36. Stark CM, Graham-Kiefer ML, Devine CM, Dollahite JS, Olson CM. Online course increases nutrition professionals' knowledge, skills, and self-efficacy in using an ecological approach to prevent childhood obesity. J Nutr Educ Behav 2011;43(5):316-22.

37. Kris YL, Chan RS, Sea MM, Woo J. Nutritionist's variation in counseling style and the effect on weight change of patients attending a community based lifestyle modification program. Int $\mathrm{J}$ Environ Res Public Health 2010;7(2):413-26.

38. Shah SM, Nanan D, Rahbar MH, Rahim M, Nowshad G. Assessing obesity and overweight in a high mountain Pakistani population. Trop Med Int Health 2004;9(4):526-32.

39. Saleem MD, Ahmed G, Mulla J, Haider SS, Abbas M. Weight misperception amongst youth of a developing country: Pakistan -a cross-sectional study. BMC Public Health 2013;13:707.

40. Nanan DJ. The obesity pandemic - Implications for Pakistan. J Pak Med Assoc 2002;52(8):342-6. 